Sharif University of Technology
Scientia Iranica
Transactions E: Industrial Engineering
hCIENTIA $\quad \begin{aligned} & \text { h / scientiairanica.sharif.edu } \\ & \text { IRAN ICA }\end{aligned}$

\title{
A new nonparametric composite exponentially weighted moving average sign control chart
}

\author{
M.A. Raza ${ }^{a, *}$, M. Aslam ${ }^{\mathrm{b}}$, M. Farooq ${ }^{\mathrm{c}}$, R.A.K. Sherwani ${ }^{\mathrm{d}}$, S.H. Bhatti ${ }^{\mathrm{a}}$, and \\ T. Ahmad ${ }^{a}$ \\ a. Department of Statistics, Government College University Faisalabad, Faisalabad 38000, Pakistan. \\ b. Department of Statistics, Faculty of Science, King Abdulaziz University, Jeddah 21551, Saudi Arabia. \\ c. Department of Statistics, Government College University Lahore, Pakistan. \\ d. College of Statistical and Actuarial Sciences, University of the Punjab Lahore, Pakistan.
}

Received 3 March 2019; received in revised form 6 April 2020; accepted 6 June 2020

\section{KEYWORDS}

Average run length;

Binomial distribution;

EWMA statistic;

Nonparametric control

charts;

Statistical process

control.

\begin{abstract}
This study proposed a dual Exponentially Weighted Moving Average (EWMA) statistics based nonparametric sign control chart to monitor the process deviation from the targeted value. The performance of the proposed chart is compared with the existing nonparametric version of the EWMA sign and Cumulative Sum (CUSUM) mean control charts by using out-of-control average run length for various shifts in the process. The simulation study showed the superiority of the suggested chart over the existing counterparts. A real dataset is also considered for the application of the proposed chart.
\end{abstract}

(C) 2022 Sharif University of Technology. All rights reserved.

\section{Introduction}

Statistical Process Control (SPC) plays an essential role in monitoring and identifying the changes in the process by using well-established statistical tools. These changes are measured in terms of variations, which can be classified into common and assignable causes of variations. The common causes of variations represent an inherent part of the process, leading to the state of statistical in-control [1]. The SPC has gained a considerable progress after the development of the Shewhart control chart [2]. Subsequently, the Cumulative Sum (CUSUM) control chart [3] and the Exponentially

\footnotetext{
*. Corresponding author. Tel.: +923214122042 E-mail addresses: ali.raza@gcuf.edu.pk (M.A. Raza); aslam_ravian@hotmail.com (M. Aslam); muhammad.farooq@gcu.edu.pk (M.Farooq); rehan.stat@pu.edu.pk (R.A.K. Sherwani); goodhaider@gmail.com (S.H.Bhatti); dr_tanvir@gcuf.edu.pk (T.Ahmad).
}

Weighted Moving Average (EWMA) control chart [4] have made a considerable improvement. The Shewhart control chart is useful in detecting larger shifts in the process as it is based on current sample information only, whereas the CUSUM and EWMA control charts utilize both the current and previous observations and, therefore, are more sensitive to identifying small to moderate shifts.

In order to combine the advantages of the Shewhart control charts in detecting larger shifts and the CUSUM control charts in detecting smaller shifts, the combined Shewhart-CUSUM chart was developed by adding Shewhart limits in the CUSUM chart [5]. A similar scheme was proposed by Lucas and Saccucci [6] by combining the Shewhart scheme with the EWMA control chart. Moreover, Abbas et al. [7] proposed a mixed EWMA-CUSUM control chart to enhance the sensitivity of the conventional memory control charts for smaller shifts. In the same context, Haq [8,9] developed a Hybrid Exponentially Weighted Moving Average (HEWMA) control chart by using dual EWMA charting statistics. This methodology of 
combining charts allows dealing with a range of shift values effectively. To be more precise, these charts detect shifts more quickly than the classical CUSUM, EWMA, and traditional Shewhart control charts.

In the aforementioned control charts, the critical quality characteristic of the process is assumed to be normally distributed. However, in many practical situations, the distribution of the underlying process is either unknown or non-normal. This, as a result, seriously affects the efficiency of the typical control charts [10]. One of the possible alternatives in this scenario is the use of the distribution-free or nonparametric control charts which are generally robust, flexible, and more effective. According to Chakraborti and Graham [11], the In-Control (IC) average runlength of all continuous distributions remains the same in distribution-free or nonparametric control charts.

In the context of nonparametric control charts, a new idea was proposed by Yang and Cheng [12] by introducing the process proportion, and a nonparametric CUSUM mean chart was suggested. Subsequently, Yang et al. [13] designed the nonparametric EWMA sign control chart and indicated that their suggested chart was capable of detecting small shifts in the target process when the underlying distribution is either non-normal or unknown. The adaptive PhaseII nonparametric EWMA control chart was proposed by Liu et al. [14] to detect a range of shifts in the location parameter. Lu [15] developed a nonparametric extension of the EWMA control chart called Generally Weighted Moving Average (GWMA) sign control chart to enhance the detection ability for small process shifts. Abbasi et al. [16] investigated the performance of the nonparametric EWMA control chart by using asymptotic, time-varying, and fast initial response based control limits. A mixed version of the EWMACUSUM sign chart was proposed by Abbasi et al. [17] using arcsine transformation and they demonstrated that the performance of their chart outperformed other counterparts in terms of shift detection. The synthetic version of the EWMA sign control chart was proposed by Haq [18] by integrating the existing EWMA sign control chart with the conforming run length. Recently, Raza et al. [19] proposed the nonparametric homogeneously weighted moving average control charts based on sign and signed-rank statistics. For more details of nonparametric control charts, we refer the interested readers to, for example, Altukife [20,21], Amin et al. [22], Aslam et al. [23], Bakir [24-26], Chowdhury et al. [27], Graham et al. [28-31], Koutras and Triantafyllou [32], Mahmood et al. [33], Raza et al. [34], and the references cited therein.

In this paper, a nonparametric Composite Exponentially Weighted Moving Average (CEWMA) control chart was proposed by combining two EWMA statistics that enhance the sensitivity of the chart. Note that
Haq $[8,9]$ designed an HEWMA control chart using two EWMA statistics under the assumption that the underlying distribution of the quality characteristic is normal. However, this chart is not effective in case of violation of normality assumption or when the distribution is unknown which happens to be the most practical situation. Furthermore, the variance expression derived by Haq [8,9] becomes undefined when $\lambda_{1}=$ $\lambda_{2}$. The nonparametric version of a double EWMA control chart was proposed by Riaz and Abbasi [35] using arcsine transformation, and the same value of smoothing constant $\lambda$ was assumed for both EWMA statistics. This makes the use of their chart limited for practitioners if they want to use different values for smoothing parameters. On the contrary, our proposed chart is simple as it considers a sign test without any transformation to define a composite EWMA charting statistic. Furthermore, the CEWMA chart provides greater flexibility than the one proposed by Riaz and Abbasi [35] by allowing practitioners to consider all possible combinations of smoothing parameters $\lambda_{1}$ and $\lambda_{2}$. Besides, we have evaluated the performance of the proposed control chart under various distributions, which had not been considered by Riaz and Abbasi [35].

The rest of this paper is organized as follows. The design structure of the proposed CEWMA sign control chart is given in Section 2. Performance evaluations of the proposed charts are given in Section 3. Section 4 reports comparisons with the existing control charts using out-of-control average run length for various shifts as well as simulated real-life data examples. Finally, some conclusions are drawn in Section 5.

\section{The proposed nonparametric CEWMA sign chart}

Suppose that in a production process, a certain quality characteristic $Y$ has a median $\eta$ as a target value. Moreover, assume that $Z=Y-\eta$ denotes the process deviation from the target value with probability $p=$ $P(Z>0)$. The proposed chart is based on the sign test in which we test the hypothesis that the probability of a plus sign of $Z$ equals the probability of a minus sign, which is equivalent to the test hypothesis that the process has a specific target value, say $\eta$. Therefore, the process is said to be IC if $p=p_{0}=0.5$; otherwise, the process is deemed to be Out-Of-Control (OOC), i.e., $p=p_{1} \neq p_{0}$. Let $\left\{Y_{i t}, 1 \leq i \leq n\right\}$ be an independently and identically distributed sample taken at time $t$ from $Y$ to investigate the variation from the process target value $\eta$. Then, we define:

$$
\begin{gathered}
Z_{i t}=Y_{i t}-\eta \text { and } I_{i t}= \begin{cases}1, & \text { if } Z_{i t}>0 \\
0, & \text { otherwise }\end{cases} \\
\text { for } i=1,2, \cdots \text { and } t=1,2, \cdots
\end{gathered}
$$


Let $S_{t}$ be the number of observations for which $Z_{i t}$, $i=1,2, \cdots, n$, is greater than zero; then, the statistic $S_{t}=\sum_{i=1}^{n} I_{i t}$ follows the binomial distribution with parameters $(n, 0.50)$ for an IC process. Based on this assumption, the CEWMA sign chart is proposed by combining the two EWMA statistics as follows:

$$
\begin{array}{ll}
H E_{S_{t}}=\lambda_{1} E_{S_{t}}+\left(1-\lambda_{1}\right) H E_{S_{t-1}} & 0<\lambda_{1} \leq 1, \\
E_{S_{t}}=\lambda_{2} S_{t}+\left(1-\lambda_{2}\right) E_{S_{t-1}} & 0<\lambda_{2} \leq 1,
\end{array}
$$

where $S_{t}$ is the $t$ th successively recorded number of $Z_{t}(>0)$. Note that the mean value of $S_{t}$ is taken as the initial value of the EWMA statistics, i.e., $H E_{S_{0}}=$ $E_{S_{0}}=\mu=n p_{0}=n / 2$ and $H E_{S_{t}}$ is the monitoring statistic of the proposed CEWMA control chart. By expanding Eqs. (1) and (2), we obtain:

$$
\begin{aligned}
& H E_{S_{t}}=\left(1-\lambda_{1}\right)^{t} H E_{S_{0}}+\lambda_{1} \sum_{i=0}^{t-1}\left(1-\lambda_{1}\right)^{i} E_{S_{t-i}}, \\
& E_{S_{t}}=\left(1-\lambda_{2}\right)^{t} E_{S_{0}}+\lambda_{2} \sum_{j=0}^{t-1}\left(1-\lambda_{2}\right)^{j} S_{t-j},
\end{aligned}
$$

and then by substituting Eq. (4) into Eq. (3), we get:

$$
\begin{aligned}
H E_{S_{t}}= & \left(1-\lambda_{1}\right)^{t} \mu+\lambda_{1} \sum_{i=0}^{t-1}\left(1-\lambda_{1}\right)^{i}\left(1-\lambda_{2}\right)^{t-i} \mu \\
& +\lambda_{1} \lambda_{2} \sum_{i=0}^{t-1}\left(1-\lambda_{1}\right)^{i} \sum_{j=0}^{t-i-1}\left(1-\lambda_{2}\right)^{j} S_{t-i-j}, \quad(5) \\
= & \left(1-\lambda_{1}\right)^{t}\left(n p_{0}\right)+\lambda_{1} \sum_{i=0}^{t-1}\left(1-\lambda_{1}\right)^{i}\left(1-\lambda_{2}\right)^{t-i}\left(n p_{0}\right) \\
& +\lambda_{1} \lambda_{2} \sum_{i=1}^{t}\left(\left(1-\lambda_{2}\right)^{t-i} \sum_{j=0}^{t-i}\left(\frac{1-\lambda_{1}}{1-\lambda_{2}}\right)^{j}\right) S_{i} .
\end{aligned}
$$

After some algebraic computation of Eq. (6), we can obtain the mean of $H E_{S_{t}}$ as:

$$
E\left(H E_{S_{t}}\right)=n p_{0} .
$$

Now, by definition, the variance of $H E_{S_{t}}$ can be obtained as follows:

$$
V\left(H E_{S_{t}}\right)=\left(\lambda_{1} \lambda_{2}\right)^{2} \sum_{i=1}^{t}\left(1-\lambda_{1}\right)^{2(t-i)}
$$

$$
\left(\sum_{j=0}^{t-i}\left(\frac{1-\lambda_{1}}{1-\lambda_{2}}\right)^{j}\right)^{2} V\left(S_{i}\right)
$$

where $V\left(S_{i}\right)=n p_{0}\left(1-p_{0}\right)$. After some algebraic computation, we obtain the variance of $H E_{S_{t}}$ as:

$$
\begin{gathered}
V\left(H E_{S_{t}}\right)=\left(\frac{\lambda_{1} \lambda_{2}}{\lambda_{1}-\lambda_{2}}\right)^{2}\left[\sum_{i=1}^{2} \frac{\left(1-\lambda_{i}\right)^{2}\left(1-\left(1-\lambda_{i}\right)^{2 t}\right)}{1-\left(1-\lambda_{i}\right)^{2}}\right. \\
\left.-\frac{2\left(1-\lambda_{1}\right)\left(1-\lambda_{2}\right)\left\{1-\left(1-\lambda_{1}\right)^{t}\left(1-\lambda_{2}\right)^{t}\right\}}{1-\left(1-\lambda_{1}\right)\left(1-\lambda_{2}\right)}\right] \\
\left\{n p_{0}\left(1-p_{0}\right)\right\} .
\end{gathered}
$$

For $\lambda_{1}=\lambda_{2}=\lambda$, Eq. (5) reduces to:

$$
\begin{aligned}
H E_{S_{t}}= & (1+\lambda t)(1-\lambda)^{t}\left(n p_{0}\right) \\
& +\lambda^{2} \sum_{i=1}^{t}(t-i+1)(1-\lambda)^{t-i} S_{i} .
\end{aligned}
$$

By definition of variance, we obtain:

$$
V\left(H E_{S_{t}}\right)=\lambda^{4} \sum_{i=1}^{t}(t-i+1)^{2}(1-\lambda)^{2(t-i)} V\left(S_{i}\right),
$$

which yields:

$$
V\left(H E_{S_{t}}\right)=\lambda^{4} \sum_{i=1}^{t} i^{2}(1-\lambda)^{2(i-1)}\left\{n p_{0}\left(1-p_{0}\right)\right\}
$$

and after some algebraic work, we finally obtain $\mathrm{Eq}$. (10) as shown in Box I for the variance of Eq. (9). Now, the center line and control limits of the CEWMA sign chart are computed as follows:

$$
\begin{aligned}
& U C L=n p_{0}+k \sqrt{V\left(H E_{S_{t}}\right)}, \\
& C L=n p_{0}, \\
& L C L=n p_{0}-k \sqrt{V\left(H E_{S_{t}}\right)},
\end{aligned}
$$

where $k$ denotes the distance of the control limits from the center line in multiples of the standard deviation of the CEWMA statistic $\left(H E_{S_{t}}\right)$. The three parameters $\lambda_{1}, \lambda_{2}$, and $k$ are chosen in such a way that a specific IC Average Run Length (ARL) is achieved. Note that if any $H E_{S_{t}} \geq U C L$ or $H E_{S_{t}} \leq L C L$, the process is considered to be OOC. Furthermore, if we select $\lambda_{1}=1$ or $\lambda_{2}=1$, the CEWMA sign control chart reduces to the EWMA sign chart proposed by Yang et al. [13].

$$
V\left(H E_{S_{t}}\right)=\lambda^{4} \frac{\left\{1+(1-\lambda)^{2}\right\}-(1-\lambda)^{2 t}\left[(1+t)^{2}-\left(-1+2 t+2 t^{2}\right)(1-\lambda)^{2}+t^{2}(1-\lambda)^{4}\right]}{\left\{1-(1-\lambda)^{2}\right\}^{3}}\left\{n p_{0}\left(1-p_{0}\right)\right\}
$$




\section{Performance evaluation}

The ARL is commonly used to assess the performance of a control chart. Recall that the ARL is the average number of points plotted on a control chart before an OOC signal is shown. In this study, the Monte Carlo simulation is employed to calculate the coefficient values $k$ for various combinations of $\lambda_{1}$ and $\lambda_{2}$ after fixing $A R L_{0}=370$ and $n=10$. To get the average results, we use 100,000 repetitions for each Monte Carlo simulation. Since the distribution of $S_{t}$ in CEWMA sign statistic follows a binomial distribution, the exact $A R L_{0}=370$ is not always attained. We, therefore, find the $k$ values such that the $A R L_{0}$ is approximately equal to 370 (i.e., $A R L_{0} \approx 370$ ). Some choices of design parameters of the CEWMA sign chart under a nominal $A R L_{0}$ value of 370 are given in Table 1.

The control limits of the proposed chart depend on $n, k, \lambda_{1}$, and $\lambda_{2}$. It can be observed from Table 1 that the values of $k$ are symmetrical with respect to $\lambda_{1}$ and $\lambda_{2}$. There is an increasing trend in $k$ by increasing either $\lambda_{1}, \lambda_{2}$ or both, except for larger values of $\lambda_{1}$ and $\lambda_{2}$. The same strategy can be applied to find the values of $k$ for various $n$ 's. In addition to the $A R L_{0}$, the OOC run length $\left(A R L_{1}\right)$ is also calculated which is expected to be adequately small (for a fixed $A R L_{0}$ ) to detect the process shift quickly. Considering the IC process proportion $p_{0}=0.50$ and $\lambda_{1}=\lambda_{2}=\lambda=$ 0.05 , the $A R L_{1}$ values of the CEWMA sign chart are computed in Table 2 by using different values of $n$ and the expected OOC process proportion $\left(p_{1}\right)$. Besides, the performance of the CEWMA sign chat is also investigated for $\lambda_{1} \neq \lambda_{2}$. In this scenario, the ARL values for smoothing constants $\left(\lambda_{1}=0.05, \lambda_{2}=0.10\right)$ and $\left(\lambda_{1}=0.05, \lambda_{2}=0.20\right)$ under various $n$ and $p_{1}$ are presented in Tables 3 and 4 , respectively. When $p=0.50$, the attained $A R L_{0}$ values are approximately equal to the desired value of 370 . From Tables $2-4$, it can be noticed that $A R L_{1}$ values are inversely related to $\left|p_{1}-0.50\right|$ and $n$. It can also be observed that $k$ changes marginally as the sample size $n$ increases. Moreover, for smaller shifts, the $A R L_{1}$ values increase marginally with increase in one of the smoothing constants $\lambda_{1}$ and $\lambda_{2}$.

In the following, we further investigate the performance of the proposed CEWMA control chart under the assumption that the critical quality characteristic of a process follows some specific distribution. The performance of the proposed CEWMA control chart under various symmetrical and asymmetrical distributions is assessed by using different run-length characteristics such as ARL, median run length ( $M D R L)$, and Standard Deviation Run Length $(S D R L)$. To be more precise, by setting $A R L_{0}=370$, the run length distribution for $\lambda_{1}=\lambda_{2}=0.05$ and $n=10$ is computed under the standard normal distribution, $N(0,1)$; the Student's $t$ distribution with 4 and 8 degrees of freedom; the heavy-tailed symmetric distributions that include the Laplace (or double exponential) distribution Laplace $(0,1 / \sqrt{2})$, the Logistic distribution $L G(0, \sqrt{3} / \pi)$, the Weibull distribution Weibull $(2,1)$, the Gamma distribution $\operatorname{Gamma}(4,1)$, and the contaminated normal $(C N)$ distribution. Recall that the $C N$ distribution is obtained by combining two normal distributions $N\left(0, \sigma_{1}^{2}\right)$ and $N\left(0, \sigma_{2}^{2}\right)$ using the relation $(1-\varphi) N\left(0, \sigma_{1}^{2}\right)+\varphi N\left(0, \sigma_{2}^{2}\right)$, where $\varphi$ denotes the proportion of contamination. This distribution is generally used to evaluate the outlier resistance power of the control charts. In our study, we set $\sigma_{1}^{2}=4 \sigma_{2}^{2}$ and the proportion of contamination $\varphi=0.10$. To

Table 1. The $k$ values with different combinations of $\left(\lambda_{1}, \lambda_{2}\right)$ for $A R L_{0} \approx 370$ and $n=10$.

\begin{tabular}{cccccccccccc}
\hline \multirow{2}{*}{$\boldsymbol{\lambda}_{\mathbf{2}}$} & \multicolumn{7}{c}{$\boldsymbol{7} \boldsymbol{\boldsymbol { \lambda } _ { \mathbf { 2 } }}$} \\
\cline { 2 - 12 } & $\mathbf{0 . 0 5}$ & $\mathbf{0 . 1 0}$ & $\mathbf{0 . 2 0}$ & $\mathbf{0 . 2 5}$ & $\mathbf{0 . 3 0}$ & $\mathbf{0 . 4 0}$ & $\mathbf{0 . 5 0}$ & $\mathbf{0 . 6 0}$ & $\mathbf{0 . 7 0}$ & $\mathbf{0 . 8 0}$ & $\mathbf{0 . 9 0}$ \\
\hline $\mathbf{0 . 0 5}$ & $\mathbf{1 . 9 5 4}$ & 2.092 & 2.227 & 2.271 & 2.304 & 2.353 & 2.392 & 2.428 & 2.455 & 2.481 & 2.505 \\
$\mathbf{0 . 1 0}$ & 2.092 & $\mathbf{2 . 2 4 5}$ & 2.387 & 2.429 & 2.468 & 2.526 & 2.562 & 2.598 & 2.629 & 2.66 & 2.682 \\
$\mathbf{0 . 2 0}$ & 2.227 & 2.387 & $\mathbf{2 . 5 2 8}$ & 2.571 & 2.61 & 2.666 & 2.711 & 2.744 & 2.772 & 2.795 & 2.822 \\
$\mathbf{0 . 2 5}$ & 2.271 & 2.429 & 2.571 & $\mathbf{2 . 6 1 9}$ & 2.655 & 2.71 & 2.751 & 2.784 & 2.809 & 2.832 & 2.852 \\
$\mathbf{0 . 3 0}$ & 2.304 & 2.468 & 2.61 & 2.655 & $\mathbf{2 . 6 9 2}$ & 2.743 & 2.782 & 2.811 & 2.837 & 2.855 & 2.871 \\
$\mathbf{0 . 4 0}$ & 2.353 & 2.526 & 2.666 & 2.71 & 2.743 & $\mathbf{2 . 7 9 2}$ & 2.825 & 2.853 & 2.871 & 2.878 & 2.883 \\
$\mathbf{0 . 5 0}$ & 2.392 & 2.562 & 2.711 & 2.751 & 2.782 & 2.825 & $\mathbf{2 . 8 5 6}$ & 2.875 & 2.884 & 2.889 & 2.892 \\
$\mathbf{0 . 6 0}$ & 2.428 & 2.598 & 2.744 & 2.784 & 2.811 & 2.853 & 2.875 & $\mathbf{2 . 8 8 4}$ & 2.89 & 2.893 & 2.885 \\
$\mathbf{0 . 7 0}$ & 2.455 & 2.629 & 2.772 & 2.809 & 2.837 & 2.871 & 2.884 & 2.89 & $\mathbf{2 . 8 9 4}$ & 2.882 & 2.868 \\
$\mathbf{0 . 8 0}$ & 2.481 & 2.66 & 2.795 & 2.832 & 2.855 & 2.878 & 2.889 & 2.893 & 2.882 & $\mathbf{2 . 8 6 8}$ & 2.855 \\
$\mathbf{0 . 9 0}$ & 2.505 & 2.682 & 2.822 & 2.852 & 2.871 & 2.883 & 2.892 & 2.885 & 2.868 & 2.855 & $\mathbf{2 . 8 2}$ \\
\hline
\end{tabular}


Table 2. The ARL values of the Composite Exponentially Weighted Moving Average (CEWMA) sign control chart for $\lambda_{1}=\lambda_{2}=\lambda=0.05$.

\begin{tabular}{|c|c|c|c|c|c|c|c|c|c|c|c|c|c|c|c|c|c|c|}
\hline & $n$ & 9 & 10 & 11 & 12 & 13 & 14 & 15 & 16 & 17 & 18 & 19 & 20 & 21 & 22 & 23 & 24 & 25 \\
\hline & $k$ & 1.956 & 1.954 & 1.962 & 1.955 & 1.953 & 1.961 & 1.958 & 1.966 & 1.956 & 1.955 & 1.963 & 1.957 & 1.964 & 1.957 & 1.955 & 1.964 & 1.957 \\
\hline & 0.05 & 1.1 & 1.1 & 1.0 & 1.0 & 1.0 & 1.0 & 1.0 & 1.0 & 1.0 & 1.0 & 1.0 & 1.0 & 1.0 & 1.0 & 1.0 & 1.0 & 1.0 \\
\hline & 0.10 & 1.3 & 1.3 & 1.1 & 1.1 & 1.1 & 1.1 & 1.1 & 1.0 & 1.0 & 1.0 & 1.0 & 1.0 & 1.0 & 1.0 & 1.0 & 1.0 & 1.0 \\
\hline & 0.15 & 1.6 & 1.6 & 1.3 & 1.3 & 1.4 & 1.2 & 1.2 & 1.1 & 1.1 & 1.1 & 1.1 & 1.1 & 1.1 & 1.0 & 1.0 & 1.0 & 1.0 \\
\hline & 0.20 & 2.0 & 2.0 & 1.6 & 1.6 & 1.7 & 1.4 & 1.4 & 1.3 & 1.3 & 1.3 & 1.2 & 1.2 & 1.3 & 1.2 & 1.2 & 1.1 & 1.1 \\
\hline & 0.25 & 2.8 & 2.6 & 2.3 & 2.2 & 2.2 & 1.9 & 1.9 & 1.7 & 1.7 & 1.7 & 1.5 & 1.5 & 1.6 & 1.4 & 1.4 & 1.3 & 1.3 \\
\hline & 0.30 & 4.1 & 3.8 & 3.4 & 3.2 & 3.2 & 2.8 & 2.7 & 2.4 & 2.4 & 2.4 & 2.1 & 2.2 & 2.1 & 2.0 & 2.0 & 1.8 & 1.8 \\
\hline & 0.35 & 7.0 & 6.3 & 5.7 & 5.4 & 5.1 & 4.7 & 4.4 & 4.1 & 4.0 & 3.9 & 3.6 & 3.5 & 3.5 & 3.2 & 3.1 & 2.9 & 2.9 \\
\hline & 0.40 & 13.8 & 12.8 & 11.5 & 10.9 & 10.3 & 9.5 & 8.9 & 8.3 & 8.0 & 7.8 & 7.2 & 7.0 & 6.9 & 6.5 & 6.3 & 6.0 & 5.9 \\
\hline & 0.45 & 42.1 & 38.6 & 35.4 & 33.6 & 31.6 & 29.7 & 28.0 & 26.2 & 25.3 & 24.7 & 23.0 & 22.3 & 21.7 & 20.5 & 20.0 & 18.9 & 18.6 \\
\hline \multirow{10}{*}{ p } & 0.50 & 371.0 & 370.8 & 370.5 & 369.5 & 371.8 & 371.7 & 371.5 & 370.4 & 370.4 & 371.4 & 371.3 & 371.9 & 379.1 & 372.8 & 369.4 & 370.9 & 371.6 \\
\hline & 0.55 & 42.0 & 38.9 & 35.1 & 33.8 & 31.6 & 29.3 & 28.1 & 26.1 & 25.2 & 24.3 & 23.1 & 22.1 & 21.7 & 20.6 & 20.0 & 18.8 & 18.7 \\
\hline & 0.60 & 14.0 & 12.8 & 11.5 & 10.8 & 10.2 & 9.5 & 9.0 & 8.3 & 7.9 & 7.8 & 7.2 & 7.1 & 6.8 & 6.5 & 6.3 & 6.0 & 5.8 \\
\hline & 0.65 & 7.0 & 6.3 & 5.7 & 5.4 & 5.1 & 4.7 & 4.4 & 4.1 & 3.9 & 3.9 & 3.5 & 3.5 & 3.4 & 3.2 & 3.1 & 2.9 & 2.9 \\
\hline & 0.70 & 4.1 & 3.8 & 3.4 & 3.3 & 3.2 & 2.8 & 2.7 & 2.4 & 2.4 & 2.4 & 2.1 & 2.1 & 2.1 & 2.0 & 2.0 & 1.8 & 1.8 \\
\hline & 0.75 & 2.8 & 2.6 & 2.3 & 2.2 & 2.2 & 1.9 & 1.9 & 1.7 & 1.7 & 1.7 & 1.5 & 1.5 & 1.6 & 1.4 & 1.4 & 1.3 & 1.3 \\
\hline & 0.80 & 2.0 & 2.0 & 1.6 & 1.6 & 1.7 & 1.4 & 1.4 & 1.3 & 1.3 & 1.3 & 1.2 & 1.2 & 1.3 & 1.1 & 1.2 & 1.1 & 1.1 \\
\hline & 0.85 & 1.6 & 1.6 & 1.3 & 1.3 & 1.3 & 1.2 & 1.2 & 1.1 & 1.1 & 1.1 & 1.1 & 1.1 & 1.1 & 1.0 & 1.0 & 1.0 & 1.0 \\
\hline & 0.90 & 1.3 & 1.3 & 1.1 & 1.1 & 1.1 & 1.1 & 1.1 & 1.0 & 1.0 & 1.0 & 1.0 & 1.0 & 1.0 & 1.0 & 1.0 & 1.0 & 1.0 \\
\hline & 0.95 & 1.1 & 1.1 & 1.0 & 1.0 & 1.0 & 1.0 & 1.0 & 1.0 & 1.0 & 1.0 & 1.0 & 1.0 & 1.0 & 1.0 & 1.0 & 1.0 & 1.0 \\
\hline
\end{tabular}

Table 3. The ARL values of the Composite Exponentially Weighted Moving Average (CEWMA) sign control chart for $\lambda_{1}=0.05$ and $\lambda_{2}=0.10$.

\begin{tabular}{|c|c|c|c|c|c|c|c|c|c|c|c|c|c|c|c|c|c|}
\hline$n$ & 9 & 10 & 11 & 12 & 13 & 14 & 15 & 16 & 17 & 18 & 19 & 20 & 21 & 22 & 23 & 24 & 25 \\
\hline$k$ & 2.097 & 2.092 & 2.105 & 2.098 & 2.10 & 2.101 & 2.098 & 2.096 & 2.101 & 2.098 & 2.096 & 2.098 & 2.095 & 2.101 & 2.097 & 2.095 & 2.096 \\
\hline 0.05 & 1.1 & 1.1 & 1.0 & 1.0 & 1.0 & 1.0 & 1.0 & 1.0 & 1.0 & 1.0 & 1.0 & 1.0 & 1.0 & 1.0 & 1.0 & 1.0 & 1.0 \\
\hline 0.10 & 1.3 & 1.3 & 1.1 & 1.1 & 1.1 & 1.0 & 1.0 & 1.0 & 1.0 & 1.0 & 1.0 & 1.0 & 1.0 & 1.0 & 1.0 & 1.0 & 1.0 \\
\hline 0.15 & 1.6 & 1.6 & 1.3 & 1.3 & 1.3 & 1.2 & 1.2 & 1.2 & 1.1 & 1.1 & 1.1 & 1.0 & 1.0 & 1.0 & 1.0 & 1.0 & 1.0 \\
\hline 0.20 & 2.1 & 2.1 & 1.7 & 1.7 & 1.7 & 1.4 & 1.4 & 1.5 & 1.3 & 1.3 & 1.4 & 1.2 & 1.2 & 1.1 & 1.2 & 1.2 & 1.1 \\
\hline 0.25 & 3.0 & 2.8 & 2.4 & 2.3 & 2.2 & 2.0 & 2.0 & 2.0 & 1.7 & 1.7 & 1.7 & 1.6 & 1.6 & 1.4 & 1.4 & 1.5 & 1.4 \\
\hline 0.30 & 4.4 & 4.1 & 3.6 & 3.4 & 3.3 & 2.9 & 2.9 & 2.8 & 2.5 & 2.5 & 2.4 & 2.3 & 2.2 & 2.0 & 2.0 & 2.0 & 1.9 \\
\hline 0.35 & 7.4 & 6.9 & 6.1 & 5.9 & 5.4 & 4.9 & 4.7 & 4.6 & 4.2 & 4.1 & 4.0 & 3.7 & 3.6 & 3.3 & 3.3 & 3.3 & 3.1 \\
\hline 0.40 & 14.7 & 13.4 & 12.3 & 11.6 & 10.8 & 10.0 & 9.6 & 9.2 & 8.6 & 8.2 & 7.9 & 7.5 & 7.2 & 6.8 & 6.6 & 6.5 & 6.2 \\
\hline 0.45 & 44.9 & 41.9 & 37.6 & 35.7 & 33.9 & 31.0 & 29.7 & 28.8 & 26.8 & 25.9 & 24.7 & 23.4 & 22.8 & 21.5 & 21.1 & 20.7 & 19.7 \\
\hline$p 0.50$ & 372.5 & 370.9 & 371.0 & 370.9 & 370.9 & 370.1 & 371.5 & 369.7 & 370.7 & 371.2 & 371.3 & 370.3 & 369.9 & 371.5 & 371.9 & 370.7 & 370.4 \\
\hline 0.55 & 44.9 & 41.5 & 37.9 & 35.6 & 33.6 & 31.1 & 29.8 & 28.5 & 26.6 & 25.8 & 24.9 & 23.8 & 22.7 & 21.8 & 21.1 & 20.7 & 19.6 \\
\hline 0.60 & 14.6 & 13.5 & 12.2 & 11.6 & 10.9 & 10.0 & 9.6 & 9.2 & 8.6 & 8.2 & 7.9 & 7.5 & 7.3 & 6.8 & 6.6 & 6.5 & 6.2 \\
\hline 0.65 & 7.3 & 6.8 & 6.1 & 5.7 & 5.4 & 4.9 & 4.8 & 4.6 & 4.2 & 4.1 & 4.0 & 3.7 & 3.6 & 3.3 & 3.3 & 3.3 & 3.1 \\
\hline 0.70 & 4.5 & 4.2 & 3.6 & 3.5 & 3.3 & 2.9 & 2.9 & 2.8 & 2.5 & 2.5 & 2.4 & 2.2 & 2.2 & 2.0 & 2.0 & 2.0 & 1.9 \\
\hline 0.75 & 3.0 & 2.8 & 2.4 & 2.3 & 2.2 & 2.0 & 2.0 & 2.0 & 1.7 & 1.7 & 1.7 & 1.6 & 1.6 & 1.4 & 1.4 & 1.5 & 1.4 \\
\hline 0.80 & 2.1 & 2.1 & 1.7 & 1.7 & 1.7 & 1.4 & 1.4 & 1.5 & 1.3 & 1.3 & 1.4 & 1.2 & 1.2 & 1.1 & 1.2 & 1.2 & 1.1 \\
\hline 0.85 & 1.6 & 1.6 & 1.3 & 1.3 & 1.3 & 1.2 & 1.2 & 1.2 & 1.1 & 1.1 & 1.1 & 1.0 & 1.0 & 1.0 & 1.0 & 1.0 & 1.0 \\
\hline 0.90 & 1.3 & 1.3 & 1.1 & 1.1 & 1.1 & 1.0 & 1.0 & 1.0 & 1.0 & 1.0 & 1.0 & 1.0 & 1.0 & 1.0 & 1.0 & 1.0 & 1.0 \\
\hline 0.95 & 1.1 & 1.1 & 1.0 & 1.0 & 1.0 & 1.0 & 1.0 & 1.0 & 1.0 & 1.0 & 1.0 & 1.0 & 1.0 & 1.0 & 1.0 & 1.0 & 1.0 \\
\hline
\end{tabular}

determine the OOC run length characteristics, the shift in the process mean is introduced in terms of process standard deviation $(\sigma)$, i.e., $\mu_{1}=\mu_{0}+\delta \sigma$ where $\delta$ determines the magnitude of the shift. The results are reported in Table 5 . It can be noticed from Table 5 that the $A R L_{0}$ values remain the same under all continuous symmetrical and asymmetrical distributions which validate the theory of nonparametric control charts. Furthermore, the $A R L_{1}$ values decline rapidly with increase in the size of the shift for all the distributions 
Table 4. The ARL values of the Composite Exponentially Weighted Moving Average (CEWMA) sign control chart for $\lambda_{1}=0.05$ and $\lambda_{2}=0.20$.

\begin{tabular}{|c|c|c|c|c|c|c|c|c|c|c|c|c|c|c|c|c|c|}
\hline$n$ & 9 & 10 & 11 & 12 & 13 & 14 & 15 & 16 & 17 & 18 & 19 & 20 & 21 & 22 & 23 & 24 & 25 \\
\hline$k$ & 2.235 & 2.227 & 2.228 & 2.230 & 2.229 & 2.227 & 2.231 & 2.230 & 2.229 & 2.232 & 2.228 & 2.230 & 2.230 & 2.230 & 2.232 & 2.228 & 2.2 \\
\hline 0.05 & 1.1 & 1.1 & 1.1 & 1.0 & 1.0 & 1.0 & 1.0 & 1.0 & 1.0 & 1.0 & 1.0 & 1.0 & 1.0 & 1.0 & 1.0 & 1.0 & 1.0 \\
\hline 0.10 & 1.3 & 1.3 & 1.3 & 1.1 & 1.1 & 1.2 & 1.0 & 1.0 & 1.0 & 1.0 & 1.0 & 1.0 & 1.0 & 1.0 & 1.0 & 1.0 & 1.0 \\
\hline 0.15 & 1.6 & 1.6 & 1.6 & 1.4 & 1.4 & 1.4 & 1.2 & 1.2 & 1.2 & 1.1 & 1.1 & 1.1 & 1.1 & 1.1 & 1.0 & 1.0 & 1.0 \\
\hline 0.20 & 2.2 & 2.1 & 2.0 & 1.7 & 1.7 & 1.7 & 1.5 & 1.5 & 1.5 & 1.4 & 1.4 & 1.2 & 1.2 & 1.3 & 1.2 & 1.2 & 1.2 \\
\hline 0.25 & 3.0 & 2.9 & 2.8 & 2.4 & 2.4 & 2.3 & 2.0 & 2.0 & 2.0 & 1.8 & 1.8 & 1.6 & 1.6 & 1.6 & 1.5 & 1.5 & 1.5 \\
\hline 0.30 & 4.6 & 4.3 & 4.0 & 3.6 & 3.5 & 3.3 & 3.0 & 2.9 & 2.8 & 2.6 & 2.5 & 2.3 & 2.3 & 2.3 & 2.1 & 2.1 & 2.1 \\
\hline 0.35 & 7.6 & 7.0 & 6.6 & 6.0 & 5.7 & 5.4 & 4.9 & 4.7 & 4.6 & 4.2 & 4.2 & 3.8 & 3.7 & 3.7 & 3.4 & 3.4 & 3.3 \\
\hline 0.40 & 15.1 & 13.9 & 12.9 & 11.8 & 11.2 & 10.6 & 9.9 & 9.4 & 9.0 & 8.6 & 8.2 & 7.7 & 7.5 & 7.3 & 6.9 & 6.7 & 6.6 \\
\hline 0.45 & 47.1 & 43.4 & 40.8 & 37.3 & 35.5 & 33.5 & 31.2 & 29.5 & 28.4 & 26.7 & 25.9 & 24.7 & 23.7 & 23.2 & 22.0 & 21.4 & 20.7 \\
\hline$p 0.50$ & 371.2 & 369.1 & 370.4 & 371.4 & 371.8 & 370.8 & 369.8 & 370.3 & 370.7 & 370.3 & 371.6 & 369.7 & 370.5 & 369.2 & 370.7 & 371.1 & 370.0 \\
\hline 0.55 & 47.8 & 43.8 & 40.8 & 37.4 & 35.6 & 33.0 & 31.3 & 29.7 & 28.5 & 27.0 & 25.9 & 24.3 & 23.9 & 23.0 & 22.0 & 21.2 & 20.8 \\
\hline 0.60 & 15.1 & 13.9 & 12.9 & 11.9 & 11.2 & 10.7 & 9.9 & 9.4 & 9.0 & 8.6 & 8.3 & 7.8 & 7.5 & 7.3 & 6.9 & 6.7 & 6.6 \\
\hline 0.65 & 7.6 & 7.0 & 6.5 & 6.0 & 5.7 & 5.4 & 5.0 & 4.7 & 4.6 & 4.3 & 4.2 & 3.8 & 3.7 & 3.7 & 3.4 & 3.4 & 3.3 \\
\hline 0.70 & 4.6 & 4.3 & 4.0 & 3.6 & 3.5 & 3.4 & 3.0 & 2.9 & 2.8 & 2.6 & 2.5 & 2.3 & 2.3 & 2.3 & 2.1 & 2.1 & 2.1 \\
\hline 0.75 & 3.0 & 2.9 & 2.8 & 2.4 & 2.4 & 2.3 & 2.0 & 2.0 & 2.0 & 1.8 & 1.8 & 1.6 & 1.6 & 1.6 & 1.5 & 1.5 & 1.5 \\
\hline 0.80 & 2.1 & 2.1 & 2.0 & 1.7 & 1.7 & 1.7 & 1.5 & 1.5 & 1.5 & 1.4 & 1.4 & 1.2 & 1.2 & 1.3 & 1.2 & 1.2 & 1.2 \\
\hline 0.85 & 1.6 & 1.6 & 1.6 & 1.4 & 1.4 & 1.4 & 1.2 & 1.2 & 1.2 & 1.1 & 1.1 & 1.1 & 1.1 & 1.1 & 1.0 & 1.0 & 1.0 \\
\hline 0.90 & 1.3 & 1.3 & 1.3 & 1.1 & 1.1 & 1.2 & 1.0 & 1.0 & 1.0 & 1.0 & 1.0 & 1.0 & 1.0 & 1.0 & 1.0 & 1.0 & 1.0 \\
\hline 0.95 & 1.1 & 1.1 & 1.1 & 1.0 & 1.0 & 1.0 & 1.0 & 1.0 & 1.0 & 1.0 & 1.0 & 1.0 & 1.0 & 1.0 & 1.0 & 1.0 & 1.0 \\
\hline
\end{tabular}

considered in this study. However, the rate of decline in $A R L_{1}, M D R L_{1}$, and $S D R L_{1}$ values varies with the distribution.

\section{Performance comparison}

In this section, the performance of the proposed chart is compared with those of the existing nonparametric EWMA sign and CUSUM mean control chart by using $A R L_{1}$ values for various shifts. Besides, two examples are presented in this section. Considering $n=10,15,20, p_{0}=0.50$, and $A R L_{0}=370$, the $A R L_{1}$ curves of the nonparametric EWMA sign, CUSUM mean, and CEWMA sign control charts are shown in Figures 1-3 for various shifts in the process proportion.

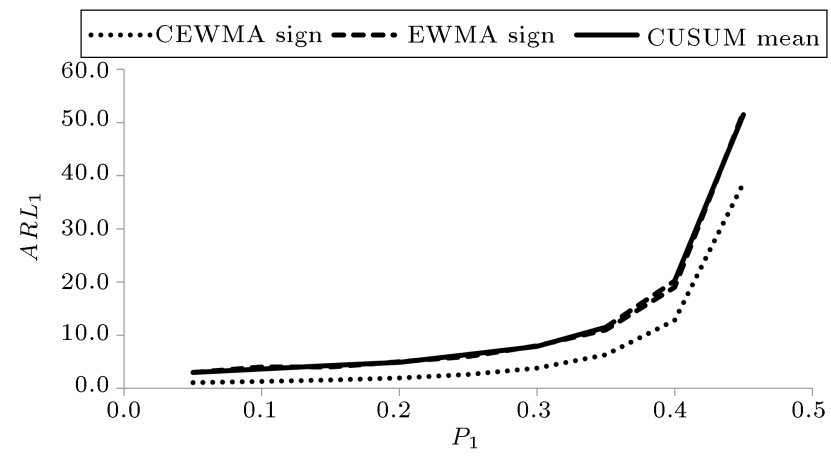

Figure 1. ARL curves of the nonparametric CEWMA sign, EWMA sign, and CUSUM mean control charts at $n=10$ and $A R L_{0} \approx 370$.

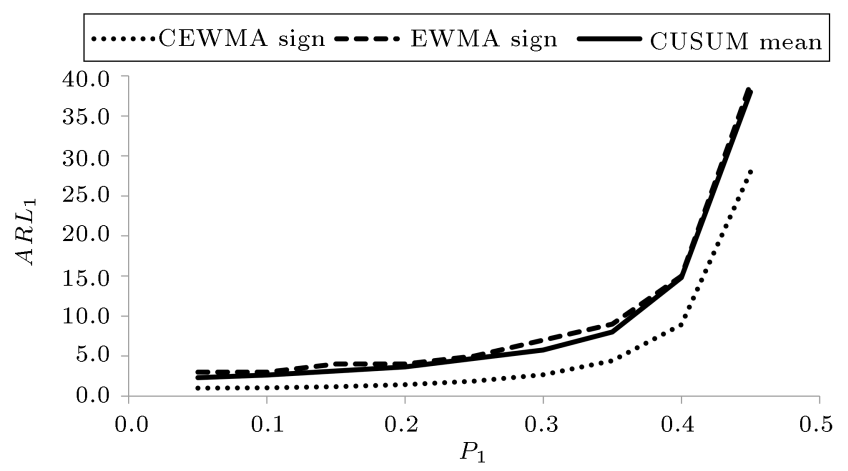

Figure 2. ARL curves of the nonparametric CEWMA sign, EWMA sign, and CUSUM mean control charts at $n=15$ and $A R L_{0} \approx 370$.

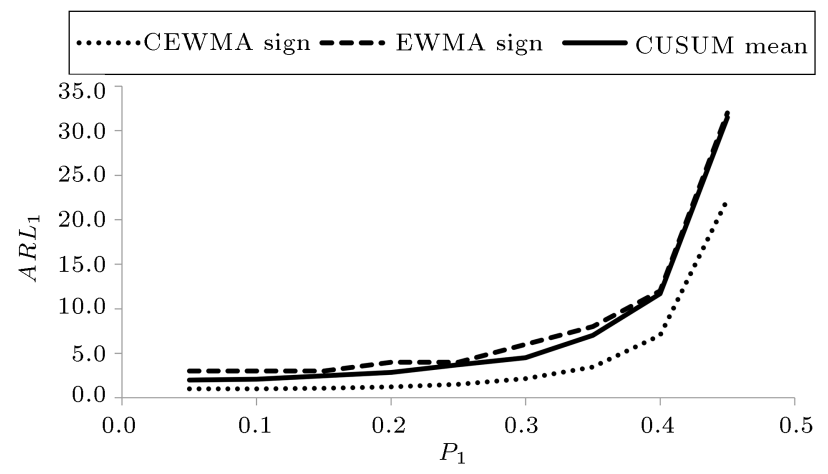

Figure 3. ARL curves of the nonparametric CEWMA sign, EWMA sign, and CUSUM mean control charts at $n=20$ and $A R L_{0} \approx 370$. 
Table 5. The run-length characteristic of the proposed Composite Exponentially Weighted Moving Average (CEWMA) chart under various distributions for $\lambda_{1}=\lambda_{2}=0.05, n=10$, and $k=1.954$ at $A R L_{0} \approx 370$.

\begin{tabular}{|c|c|c|c|c|c|c|c|c|c|c|c|c|}
\hline \multirow{2}{*}{ Distribution } & \multirow{2}{*}{ Characteristic } & \multicolumn{11}{|c|}{$\delta$} \\
\hline & & 0.00 & 0.05 & 0.10 & 0.25 & 0.50 & 0.75 & 1.00 & 1.50 & 2.00 & 2.5 & 3.0 \\
\hline \multirow{3}{*}{$N(0,1)$} & ARL & 370.8 & 141.9 & 54.2 & 12.9 & 4.1 & 2.2 & 1.6 & 1.1 & 1.0 & 1.0 & 1.0 \\
\hline & SDRL & 423.8 & 150.8 & 50.6 & 10.4 & 3.0 & 1.3 & 0.7 & 0.4 & 0.1 & 0.0 & 0.0 \\
\hline & MDRL & 235 & 97 & 42 & 10 & 3 & 2 & 1 & 1 & 1 & 1 & 1 \\
\hline \multirow{3}{*}{$t(4)$} & ARL & 371.3 & 99.3 & 35.4 & 8.2 & 2.8 & 1.7 & 1.4 & 1.1 & 1.0 & 1.0 & 1.0 \\
\hline & SDRL & 416.3 & 100.7 & 31.4 & 6.4 & 1.8 & 0.8 & 0.5 & 0.3 & 0.2 & 0.1 & 0.0 \\
\hline & MDRL & 239 & 71 & 28 & 7 & 2 & 2 & 1 & 1 & 1 & 1 & 1 \\
\hline \multirow{3}{*}{$t(8)$} & ARL & 371.1 & 126.4 & 45.7 & 10.9 & 3.5 & 2.0 & 1.5 & 1.1 & 1.0 & 1.0 & 1.0 \\
\hline & SDRL & 417.9 & 129.7 & 41.9 & 8.7 & 2.5 & 1.1 & 0.7 & 0.3 & 0.2 & 0.1 & 0.0 \\
\hline & MDRL & 237 & 88 & 36 & 9 & 3 & 2 & 1 & 1 & 1 & 1 & 1 \\
\hline \multirow{3}{*}{$C N$} & ARL & 370.3 & 128.1 & 47.2 & 11.1 & 3.6 & 2.1 & 1.5 & 1.1 & 1.0 & 1.0 & 1.0 \\
\hline & SDRL & 417.3 & 133.4 & 42.9 & 8.9 & 2.6 & 1.2 & 0.7 & 0.3 & 0.1 & 0.0 & 0.0 \\
\hline & MDRL & 234 & 88 & 37 & 9 & 3 & 2 & 1 & 1 & 1 & 1 & 1 \\
\hline \multirow{3}{*}{$L G(0, \sqrt{3} / \pi)$} & ARL & 368.4 & 123.2 & 45.0 & 10.6 & 3.4 & 2.0 & 1.5 & 1.1 & 1.0 & 1.0 & 1.0 \\
\hline & SDRL & 417.8 & 127.7 & 40.7 & 8.5 & 2.4 & 1.1 & 0.7 & 0.3 & 0.2 & 0.1 & 0.0 \\
\hline & MDRL & 235 & 86 & 36 & 9 & 2 & 2 & 1 & 1 & 1 & 1 & 1 \\
\hline \multirow{3}{*}{ Laplace $(0,1 / \sqrt{2})$} & ARL & 369.2 & 69.8 & 25.1 & 6.4 & 2.6 & 1.7 & 1.4 & 1.1 & 1.0 & 1.0 & 1.0 \\
\hline & SDRL & 412.8 & 67.2 & 21.2 & 4.9 & 1.6 & 0.8 & 0.6 & 0.3 & 0.2 & 0.1 & 0.1 \\
\hline & MDRL & 237 & 52 & 20 & 5 & 2 & 2 & 1 & 1 & 1 & 1 & 1 \\
\hline \multirow{3}{*}{$\operatorname{Gamma}(4,1)$} & ARL & 371.6 & 132.7 & 50.5 & 12.4 & 4.1 & 2.3 & 1.7 & 1.2 & 1.0 & 1.0 & 1.0 \\
\hline & SDRL & 415.9 & 140.3 & 46.4 & 10.0 & 3.0 & 1.4 & 0.8 & 0.4 & 0.2 & 0.1 & 0.0 \\
\hline & MDRL & 237 & 91 & 39 & 10 & 3 & 2 & 2 & 1 & 1 & 1 & 1 \\
\hline \multirow{3}{*}{ Weibull $(2,1)$} & $\mathrm{ARL}$ & 369.7 & 165.1 & 68.5 & 17.5 & 6.5 & 3.9 & 2.8 & 1.9 & 1.6 & 1.4 & 1.3 \\
\hline & SDRL & 415.6 & 174.6 & 64.9 & 14.3 & 5.1 & 2.8 & 1.8 & 1.0 & 0.7 & 0.6 & 0.5 \\
\hline & MDRL & 237 & 113 & 52 & 14 & 5 & 3 & 2 & 2 & 1 & 1 & 1 \\
\hline
\end{tabular}

It can be observed that the nonparametric EWMA sign and CUSUM mean control charts produce almost similar results and the proposed CEWMA sign control chart remains on the lower side for all shifts. This shows that the proposed chart outperforms for all shifts of $p_{1}$ and for different sample sizes.

\subsection{Example 1}

To illustrate the shift detection ability of the CEWMA sign and EWMA sign control charts, the following example with description taken from Montgomery [36] is considered.

"The fill volume of soft-drink beverage bottles is an important quality characteristic. The volume is measured (approximately) by placing a gauge over the crown and comparing the height of the liquid in the neck of the bottle against a coded scale. On this scale, a reading of zero corresponds to the correct fill height".

In this example, we have 15 subgroups each which with size of 10 and the target value of 0 . By choosing $\lambda=0.05$ and $k=2.49$ at $A R L_{0} \approx 370$, we obtain 4.36 and 5.63 as the lower and upper control limits for the EWMA sign chart, respectively. The monitoring statistic $E_{S_{t}}$ of the EWMA sign chart is computed and plotted against their respective control limits in Figure 4. We see that the nonparametric EWMA sign chart detects an OOC signal in sample 13. For rational evaluation of the EWMA sign scheme, the proposed nonparametric CEWMA sign chart is constructed by considering $\lambda_{1}=\lambda_{2}=\lambda=0.05$ and $k=1.954$, as shown in Figure 5. The last two columns of Table 6 show time-varying lower and upper control limits of 


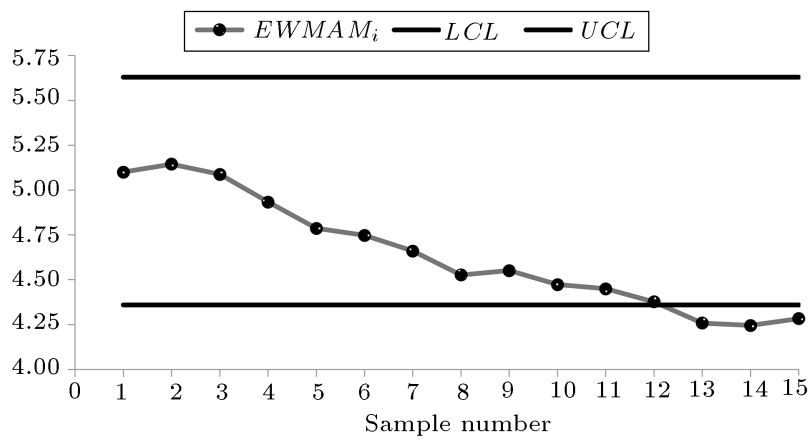

Figure 4. Nonparametric EWMA sign control chart for the fill height data using $\lambda=0.05$ and $k=2.49$ at $A R L_{0} \approx 370$.

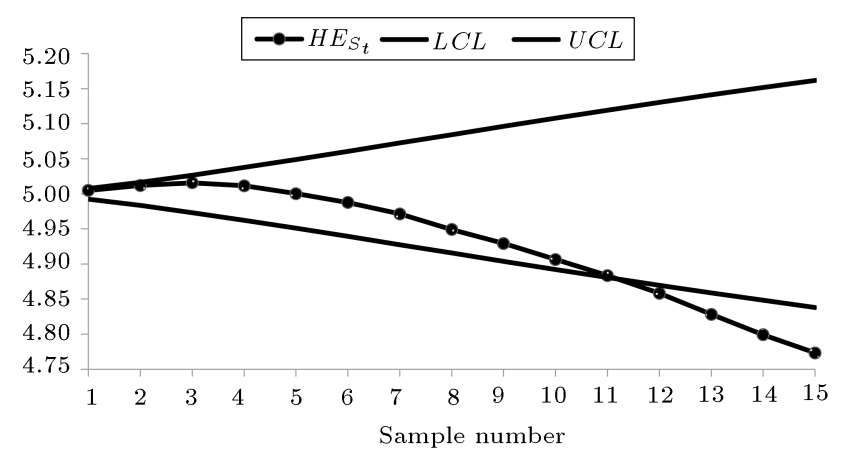

Figure 5. Nonparametric CEWMA sign chart for the fill height data using $\lambda_{1}=\lambda_{2}=0.05$ and $k=1.954$ at $A R L_{0} \approx 370$.

the CEWMA sign chart. Here, we notice that the proposed chart has identified the OOC signal in sample 12. This shows that the nonparametric CEWMA sign chart performs better than the nonparametric EWMA sign chart regarding the quick detection of the process shift.

\subsection{Example 2}

To demonstrate the detection ability of the proposed CEWMA sign chart for the dataset from a skewed distribution, 40 samples of size 15 are generated separately from the gamma distribution. The first 30 samples are generated from a gamma distribution with shape parameter 4 and the rate parameter 1 (IC process). Assuming the shift in shape parameter to 4.25 and the rate parameter to 1 (OOC process), the next 10 samples are then generated from this shifted gamma distribution. The average values of the two different gamma-distributed samples are 3.91 and 4.3, respectively. Based on the aforementioned information, parametric and nonparametric control charts are constructed to assess the performance of the suggested chart.

Choosing $A R L_{0}=370$, we construct the Shewhart $\bar{X}$ control chart as shown in Figure 6 and the time-varying EWMA control chart with $\lambda=0.05$ and $L=2.492$, as shown in Figure 7, with the assumption that the quality characteristic is normally distributed. Furthermore, we construct three nonparametric control charts, i.e., the EWMA sign chart with parameters $\lambda=0.05$ and $k=2.49$, the CUSUM mean control chart with parameters $K_{1}=0.75$ and $H_{1}= \pm 11.30$, and the proposed CEWMA sign chart with parameters $\lambda_{1}=\lambda_{2}=\lambda=0.05$ and $k=1.958$, to guarantee that $A R L_{0} \approx 370$. The results of the nonparametric control

Table 6. Existing nonparametric Exponentially Weighted Moving Average (EWMA) sign and the proposed nonparametric Composite Exponentially Weighted Moving Average (CEWMA) sign control charts for the dataset from Montgomery [36], the fill volume of soft-drink beverage bottle.

\begin{tabular}{cccccccccccccccc}
\hline Sample & $\boldsymbol{X}_{\mathbf{1}}$ & $\boldsymbol{X}_{\mathbf{2}}$ & $\boldsymbol{X}_{\mathbf{3}}$ & $\boldsymbol{X}_{\mathbf{4}}$ & $\boldsymbol{X}_{\mathbf{5}}$ & $\boldsymbol{X}_{\mathbf{6}}$ & $\boldsymbol{X}_{\boldsymbol{7}}$ & $\boldsymbol{X}_{\mathbf{8}}$ & $\boldsymbol{X}_{\mathbf{9}}$ & $\boldsymbol{X}_{\mathbf{1 0}}$ & $\boldsymbol{S}_{\boldsymbol{t}}$ & $\boldsymbol{E}_{\boldsymbol{S}_{t}}$ & $\boldsymbol{H}_{\boldsymbol{S}_{t}}$ & $\boldsymbol{L} \boldsymbol{C L}$ & $\boldsymbol{U} \boldsymbol{C L}$ \\
\hline 1 & 2.5 & 0.5 & 2 & -1 & 1 & -1 & 0.5 & 1.5 & 0.5 & -1.5 & 7 & 5.1000 & 5.0050 & 4.9923 & 5.0077 \\
2 & 0 & 0 & 0.5 & 1 & 1.5 & 1 & -1 & 1 & 1.5 & -1 & 6 & 5.1450 & 5.0120 & 4.9834 & 5.0166 \\
3 & 1.5 & 1 & 1 & -1 & 0 & -1.5 & -1 & -1 & 1 & -1 & 4 & 5.0878 & 5.0158 & 4.9733 & 5.0267 \\
4 & 0 & 0.5 & -2 & 0 & -1 & 1.5 & -1.5 & 0 & -2 & -1.5 & 2 & 4.9334 & 5.0117 & 4.9624 & 5.0376 \\
5 & 0 & 0 & 0 & -0.5 & 0.5 & 1 & -0.5 & -0.5 & 0 & 0 & 2 & 4.7867 & 5.0004 & 4.9510 & 5.0490 \\
6 & 1 & -0.5 & 0 & 0 & 0 & 0.5 & -1 & 1 & -2 & 1 & 4 & 4.7474 & 4.9878 & 4.9393 & 5.0607 \\
7 & 1 & -1 & -1 & -1 & 0 & 1.5 & 0 & 1 & 0 & 0 & 3 & 4.6600 & 4.9714 & 4.9274 & 5.0726 \\
8 & 0 & -1.5 & -0.5 & 1.5 & 0 & 0 & 0 & -1 & 0.5 & -0.5 & 2 & 4.5270 & 4.9492 & 4.9156 & 5.0844 \\
9 & -2 & -1.5 & 1.5 & 1.5 & 0 & 0 & 0.5 & 1 & 0 & 1 & 5 & 4.5506 & 4.9292 & 4.9038 & 5.0962 \\
10 & -0.5 & 3.5 & 0 & -1 & -1.5 & -1.5 & -1 & -1 & 1 & 0.5 & 3 & 4.4731 & 4.9064 & 4.8922 & 5.1078 \\
11 & 0 & 1.5 & 0 & 0 & 2 & -1.5 & 0.5 & -0.5 & 2 & -1 & 4 & 4.4495 & 4.8836 & 4.8808 & 5.1192 \\
12 & 0 & -2 & -0.5 & 0 & -0.5 & 2 & 1.5 & 0 & 0.5 & -1 & 3 & 4.3770 & $\mathbf{4 . 8 5 8 2}$ & 4.8696 & 5.1304 \\
13 & -1 & -0.5 & -0.5 & -1 & 0 & 0.5 & 0.5 & -1.5 & -1 & -1 & 2 & $\mathbf{4 . 2 5 8 1}$ & $\mathbf{4 . 8 2 8 2}$ & 4.8588 & 5.1412 \\
14 & 0.5 & 1 & -1 & -0.5 & -2 & -1 & -1.5 & 0 & 1.5 & 1.5 & 4 & $\mathbf{4 . 2 4 5 2}$ & $\mathbf{4 . 7 9 9 1}$ & 4.8483 & 5.1517 \\
15 & 1 & 0 & 1.5 & 1.5 & 1 & -1 & 0 & 1 & -2 & -1.5 & 5 & $\mathbf{4 . 2 8 3 0}$ & $\mathbf{4 . 7 7 3 3}$ & 4.8381 & 5.1619 \\
\hline
\end{tabular}




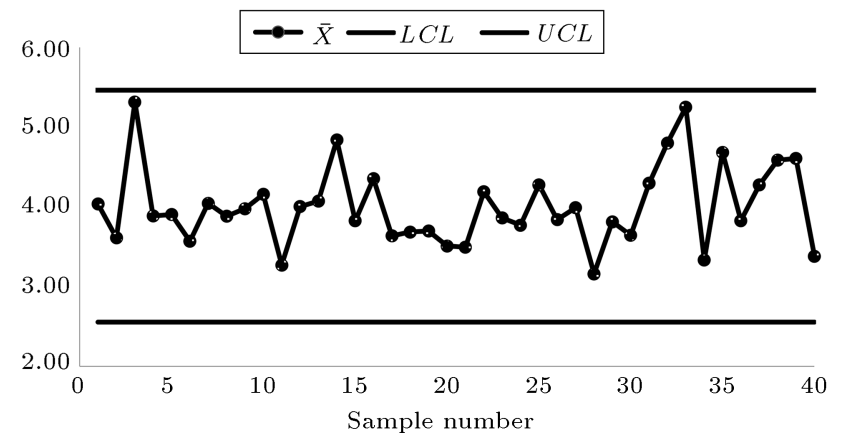

Figure 6. Shewhart $\bar{X}$ chart for the simulated data set using $A_{2}=0.223$ at $A R L_{0} \approx 370$.

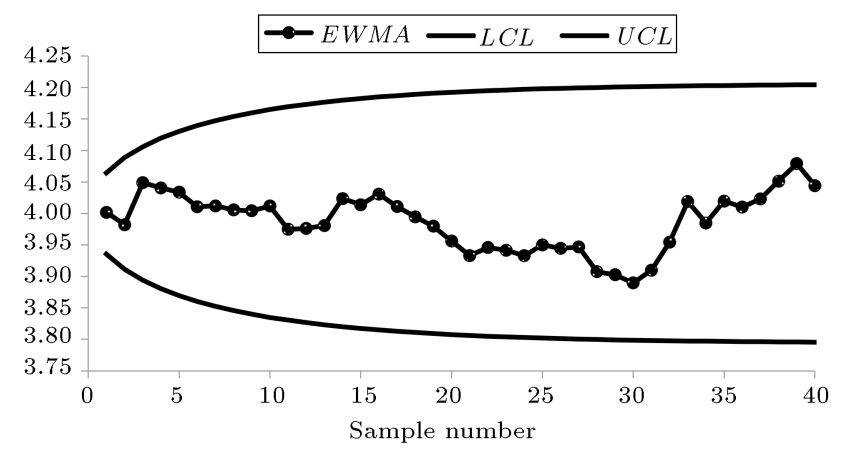

Figure 7. Classical EWMA chart for the simulated data set using $\lambda=0.05$ and $L=2.492$ at $A R L_{0} \approx 370$.

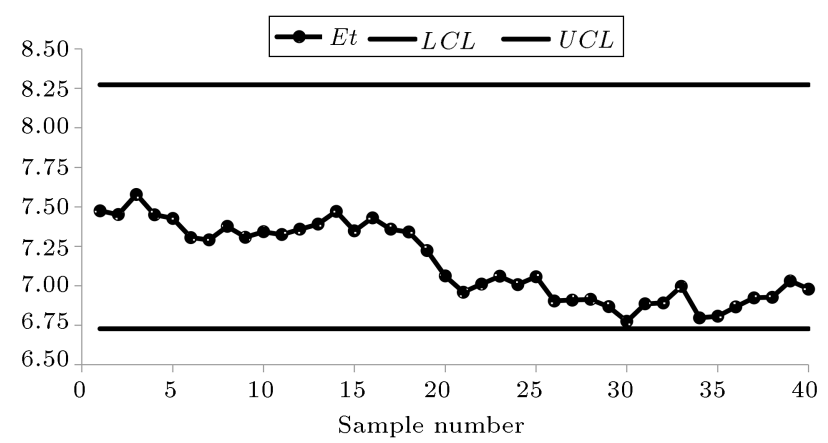

Figure 8. Nonparametric EWMA sign chart for the simulated data using $\lambda=0.05$ and $k=2.49$ at $A R L_{0} \approx 370$.

charts are provided in Table 7 and displayed graphically in Figures 8-10. In these schemes, the statistic $E_{S_{t}}$ is plotted against the control limits $L C L=6.7279$ and $U C L=8.2721$ for the nonparametric EWMA sign chart, $C_{t}^{+}$'s and $C_{t}^{-}$'s are plotted against the decision interval $H_{1}$ for the nonparametric CUSUM mean chart, and $H E_{S_{t}}$ is plotted against time-varying control limits for the proposed CEWMA sign chart.

It is apparent from Figure 10 that the suggested control chart triggers OOC signals in samples 3540, whereas Figures 6-9 show that the Shewhart $\bar{X}$, classical EWMA, nonparametric EWMA sign, and nonparametric CUSUM mean control charts fail to identify this shift in the given dataset. This example

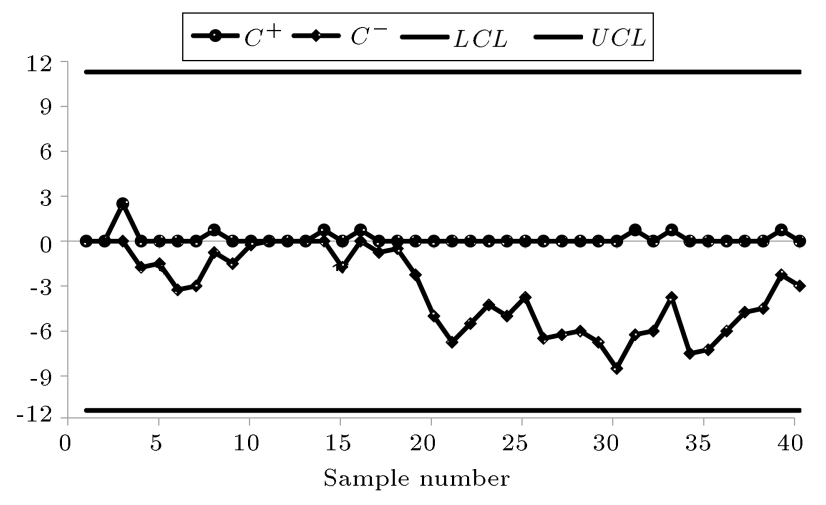

Figure 9. Nonparametric CUSUM mean control chart for the simulated data using $K_{1}=0.75$ and $H_{1}=11.30$ at $A R L_{0} \approx 370$.

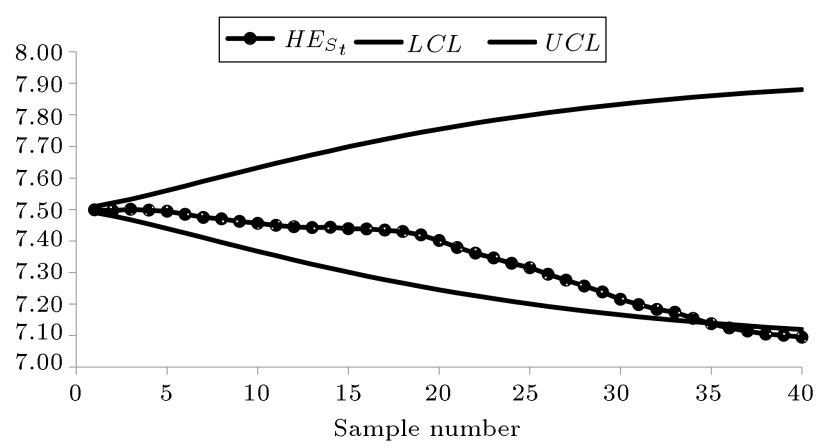

Figure 10. Nonparametric CEWMA sign control chart for the simulated data using $\lambda_{1}=\lambda_{2}=0.05$ and $k=1.958$ at $A R L_{0} \approx 370$.

points to the superiority of the proposed chart in identifying small shifts in the process over the four other competing parametric and nonparametric control charts.

\section{Conclusion}

In this study, a new nonparametric Composite Exponentially Weighted Moving Average (CEWMA) sign chart that represented the combination of two EWMA statistics was proposed. The proposed chart could be used to detect process shifts quickly, particularly smaller shifts, by using different combinations of the sensitivity parameters $\lambda_{1}$ and $\lambda_{2}$. The suggested CEWMA sign chart could attract wider applicability as the performance of the CEWMA sign chart was superior to the existing nonparametric Exponentially Weighted Moving Average (EWMA) sign chart and the nonparametric CUSUM mean chart. Furthermore, the nonparametric EWMA sign chart is a special case of the proposed CEWMA chart when either $\lambda_{1}$ or $\lambda_{2}$ equals one. The practical implementation of our proposed chart was illustrated using a real-life example. Moreover, results based on the simulation study showed that the suggested chart completely dominated the 


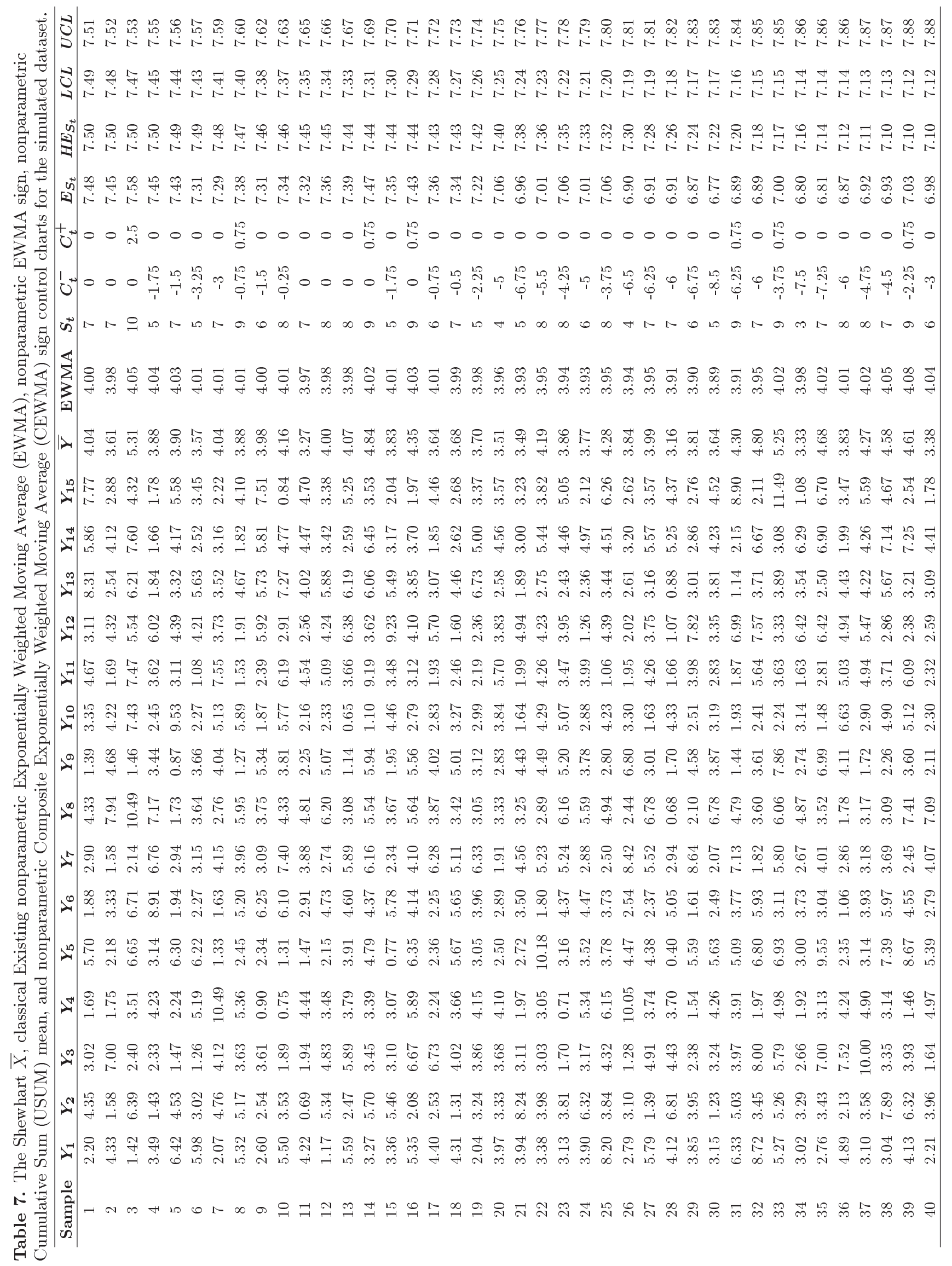


other competing parametric and nonparametric control charts in detecting smaller shifts. Hence, the use of CEWMA sign control chart is recommended for the practitioners, if complete knowledge about the underlying process distribution is not available. One can further extend this scheme by developing the CEWMA sign chart using other nonparametric tests such as the Mann-Whitney test.

\section{Acknowledgments}

The authors are thankful to the editor and anonymous referees for their valuable suggestions to improve the quality of the paper.

\section{References}

1. Qiu, P., Introduction to Statistical Process Control, Boca Raton, FL: CRC Press (2013).

2. Shewhart, W. "Economic quality control of manufactured product", Bell System Technical Journal, 9(2), pp. 364-389 (1930).

3. Page, E.S. "Continuous inspection schemes", Biometrika, 41(1/2), pp. 100-115 (1954).

4. Roberts, S. "Control chart tests based on geometric moving averages", Technometrics, 1(3), pp. 239-250 (1959).

5. Lucas, J.M. "Combined Shewhart-CUSUM quality control schemes", Journal of Quality Technology, 14(2), pp. 51-59 (1982).

6. Lucas, J.M. and Saccucci, M.S. "Exponentially weighted moving average control schemes: properties and enhancements", Technometrics, 32(1), pp. 1-12 (1990).

7. Abbas, N., Riaz, M., and Does, R.J. "Mixed exponentially weighted moving average-cumulative sum charts for process monitoring", Quality and Reliability Engineering International, 29(3), pp. 345-356 (2013).

8. Haq, A. "A new hybrid exponentially weighted moving average control chart for monitoring process mean", Quality and Reliability Engineering International, 29(7), pp. 1015-1025 (2013).

9. Haq, A. "A new hybrid exponentially weighted moving average control chart for monitoring process mean: discussion", Quality and Reliability Engineering International, 33(7), pp. 1629-1631 (2017).

10. Human, S.W., Kritzinger, P., and Chakraborti, S. "Robustness of the EWMA control chart for individual observations", Journal of Applied Statistics, 38(10), pp. 2071-2087 (2011).

11. Chakraborti, S. and Graham, M.A., Nonparametric Statistical Process Control, John Wiley \& Sons (2019).

12. Yang, S.-F. and Cheng, S.W. "A new non-parametric CUSUM mean chart", Quality and Reliability Engineering International, 27(7), pp. 867-875 (2011).
13. Yang, S.-F., Lin, J.-S., and Cheng, S.W. "A new nonparametric EWMA sign control chart", Expert Systems with Applications, 38(5), pp. 6239-6243 (2011).

14. Liu, L., Chen, B., Zhang, J., et al. "Adaptive phase II nonparametric EWMA control chart with variable sampling interval", Quality and Reliability Engineering International, 31(1), pp. 15-26 (2015).

15. Lu, S.L. "An extended nonparametric exponentially weighted moving average sign control chart", Quality and Reliability Engineering International, 31(1), pp. 3-13 (2015).

16. Abbasi, S.A., Ahmad, S., and Riaz, M. "On enhanced sensitivity of nonparametric EWMA control charts for process monitoring", Scientia Iranica, 24(1), pp. 424438 (2017).

17. Abbasi, A., Aslam, M., and Saghir, A. "A mixed nonparametric control chart for efficient process monitoring", The International Journal of Advanced Manufacturing Technology, 99, pp. 2549-2561 (2018).

18. Haq, A. "A new nonparametric synthetic EWMA control chart for monitoring process mean", Communications in Statistics-Simulation and Computation, 48(6), pp. 1665-1676 (2019).

19. Raza, M.A., Nawaz, T., and Han, D. "On designing distribution-free homogeneously weighted moving average control charts", Journal of Testing and Evaluation, 48(4), pp. 3154-3171 (2020).

20. Altukife, F.S. "A new nonparametric control chart based on the observations exceeding the grand median", Pakistan Journal of Statistics, 19(3), pp. 343352 (2003).

21. Altukife, F.S. "Nonparametric control chart based on sum of ranks", Pakistan Journal of Statistics, 19(3), pp. 291-300 (2003).

22. Amin, R.W., Reynolds Jr, M.R., and Saad, B. "Nonparametric quality control charts based on the sign statistic", Communications in Statistics-Theory and Methods, 24(6), pp. 1597-1623 (1995).

23. Aslam, M., Raza, M.A., Azam, M., et al. "Design of a sign chart using a new EWMA statistic", Communications in Statistics-Theory and Methods, 49(6), pp. 1299-1310 (2020).

24. Bakir, S.T. "A distribution-free Shewhart quality control chart based on signed-ranks", Quality Engineering, 16(4), pp. 613-623 (2004).

25. Bakir, S.T. "Distribution-free quality control charts based on signed-rank-like statistics", Communications in Statistics-Theory and Methods, 35(4), pp. 743-757 (2006).

26. Bakir, S.T. "A nonparametric shewhart-type quality control chart for monitoring broad changes in a process distribution", International Journal of Quality, Statistics, and Reliability, 2012 (2012). DOI: https://doi.org/10.1155/2012/147520

27. Chowdhury, S., Mukherjee, A., and Chakraborti, S. "Distribution-free phase II CUSUM control chart for 
joint monitoring of location and scale", Quality and Reliability Engineering International, 31(1), pp. 135151 (2015).

28. Graham, M.A., Chakraborti, S., and Human, S.W. "A nonparametric EWMA sign chart for location based on individual measurements", Quality Engineering, 23(3), pp. 227-241 (2011).

29. Graham, M.A., Chakraborti, S., and Human, S.W. "A nonparametric exponentially weighted moving average signed-rank chart for monitoring location", Computational Statistics \& Data Analysis, 55(8), pp. 2490-2503 (2011).

30. Graham, M.A., Chakraborti, S., and Mukherjee, A. "Design and implementation of CUSUM exceedance control charts for unknown location", International Journal of Production Research, 52(18), pp. 5546-5564 (2014).

31. Graham, M.A., Mukherjee, A., and Chakraborti, S. "Distribution-free exponentially weighted moving average control charts for monitoring unknown location", Computational Statistics \& Data Analysis, 56(8), pp. 2539-2561 (2012).

32. Koutras, M.V. and Triantafyllou, I.S. "A general class of nonparametric control charts", Quality and Reliability Engineering International, 34(3), pp. 427435 (2018).

33. Mahmood, T., Nazir, H.Z., Abbas, N., et al. "Performance evaluation of joint monitoring control charts", Scientia Iranica, 24(4), pp. 2152-2163 (2017).

34. Raza, M.A., Nawaz, T., Aslam, M., et al. "A new nonparametric double exponentially weighted moving average control chart", Quality and Reliability Engineering International, 36(1), pp. 68-87 (2020).

35. Riaz, M. and Abbasi, S.A. "Nonparametric double EWMA control chart for process monitoring", Revista Colombiana de Estadística, 39(2), pp. 167-184 (2016).

36. Montgomery, D.C., Introduction to Statistical Quality Control, 7th Edn., Hoboken, NJ: John Wiley \& Sons (2013).

\section{Biographies}

Muhammad Ali Raza obtained his MSc and MPhil in Statistics from the University of the Punjab Lahore, Pakistan. He earned his $\mathrm{PhD}$ in Statistics from Shanghai Jiao Tong University, the People's Republic of China in June 2019. He has been working as an Assistant Professor at the Department of Statistics, Government College University Faisalabad, Pakistan since October 2011. He has more than 20 refereed publications in various research journals. His research interests include statistical process control, probability and probability distributions, and applied statistics.

Muhammad Aslam earned his MSc in Statistics (2004) from GC University Lahore with Chief Minister of the Punjab merit scholarship, MPhil in Statistics (2006) from GC University Lahore with the Governor of the Punjab merit scholarship, and PhD in Statistics (2010) from National College of Business Administration \& Economics Lahore under the supervision of Prof. Dr. Munir Ahmad. He worked as a lecturer of Statistics in Edge College System International from 2003-2006. He also worked as a Research Assistant at the Department of Statistics, GC University Lahore from 2006 to 2008. Then, he joined the Forman Christian College University as a lecturer in August 2009. He worked as an Assistant Professor at the same University from June 2010 to April 2012. He worked at the same Department as an Associate Professor from June 2012 to October 2014. He worked as an Associate Professor of Statistics at the Department of Statistics, Faculty of Science, King Abdulaziz University, Jeddah, Saudi Arabia from October 2014 to March 2017. He taught summer courses at Visiting Faculty of Statistics at Beijing Jiao tong University, China in 2016. Currently, he is working as a Full Professor of Statistics at the Department of Statistics, King Abdulaziz University Jeddah, and Saudi Arabia. He has published more than 395 research papers in national and international well-reputed journals including, IEEE Access, Journal of Applied Statistics, European Journal of Operation Research, Information Sciences, Journal of Process Control, Journal of the Operational Research Society, etc. His papers have been cited by more than 3700 times with h-index 32 and i-10 index 106 (Google Scholar). His papers have been cited by more than 2200 times with h-index 25 (Web of Science Citations). He is the author of two books published by VDM Germany and Springer, respectively. He has published 8 chapters in wellreputed books. He has been also HEC approved $\mathrm{PhD}$ supervisor since 2011. He supervised $5 \mathrm{PhD}$ theses, more than 25 MPhil theses, and 3 MSc theses. He is a reviewer of more than 70 well-reputed international journals. He has reviewed more than 155 research papers for various well-reputed international journals. He received a meritorious services award in research from the National College of Business Administration \& Economics Lahore in 2011. He received Research Productivity Award for the year 2012 by Pakistan Council for Science and Technology. His name was listed in the 2nd position among Statisticians in the Directory of Productivity Scientists of Pakistan 2013. His name was listed in 1st Position among Statisticians in the Directory of Productivity Scientists of Pakistan 2014. He got 371 positions in the list of top 2210 profiles of Scientist of Saudi Institutions in 2016. He was selected for the "Innovative Academic Research \& Dedicated Faculty Award 2017" by SPE, Malaysia. He received King Abdulaziz University Excellence Awards in Scientific Research for the paper entitled "Aslam, 
M., Azam, M., Khan, N. and Jun, C.-H. (2015). A New Mixed Control Chart to Monitor the Process, International Journal of Production Research, 53 (15), 4684-4693". He received the King Abdulaziz University citation award for the paper entitled "Azam, M., Aslam, M. and Jun, C.-H. (2015). Designing of a hybrid exponentially weighted moving average control chart using repetitive sampling, International Journal of Advanced Manufacturing Technology, 77:1927-1933 in 2018". Prof. Muhammad Aslam pioneer in the area of Neutrosophic Statistical Quality Control (NSQC). He is the founder of Neutrosophic Inferential Statistics (NIS) and NSQC. His contribution is the development of neutrosophic statistics theory for the inspection and process control. He originally developed the theory in these areas under the neutrosophic statistics. He extended the classical statistics theory to neutrosophic statistics originally in 2018. He is a member of the editorial board of Electronic Journal of Applied Statistical Analysis, Neutrosophic Sets and Systems, Asian Journal of Applied Science and Technology, and Pakistan Journal of Commence and Social sciences. He is also a member of the Islamic Countries Society of Statistical Sciences. He was appointed as an external examiner for the 2016/2017-2018/2019 triennium at The University of Dodoma, Tanzania. His areas of interest include reliability, decision trees, industrial statistics, acceptance sampling, rank set sampling, neutrosophic statistics, and applied statistics.

Muhammad Farooq earned his $\mathrm{PhD}$ in Statistics from the University of Stuttgart, Germany in October 2018. He is working as an Assistant Professor at the
Department of Statistics, Government College University Lahore, Pakistan. His research interests include statistical learning, kernel-based learning methods, mathematical statistics, neuro-statistics, and Bayesian analysis.

Rehan Ahmed Khan Sherwani is an Associate Professor at the College of Statistical and Actuarial Sciences, University of the Punjab, Lahore, Pakistan. His areas of research include mixed models, statistical quality control, neutrosophic statistics, and computational and applied statistics.

Sajjad Haider Bhatti received his PhD in Applied Statistics and Econometrics from the University of Dijon, France. He is currently working as an Assistant Professor at the Department of Statistics, Government College University Faisalabad, Pakistan. His research interests include regression diagnostics, modified estimators, and statistical quality control.

Tanvir Ahmad received his PhD in Statistics from Islamia University Bahawalpur, Pakistan. He partially completed his PhD research in Queen Mary, University of London. He received his MSc from the Department of Statistics, Bahauddin Zakariya University, Multan. He joined the University of Southampton as a postdoctoral fellow in 2015. He is currently working as an Associate Professor of Statistics at the Department of Statistics, Government College University Faisalabad, Pakistan. His research interests include response surface methodology, robust optimization, epidemiology, and survival analysis. 